\title{
Do they want contact with us? The role of intergroup contact meta-perceptions on positive contact and attitudes
}

\begin{abstract}
This research examined the role of contact meta-perceptions on positive intergroup contact and outgroup attitudes. Specifically, perceptions of the ingroup's and outgroup's desire for intergroup contact were simultaneously tested as predictors of intergroup contact and outgroup attitudes. Three correlational studies were conducted in three distinct contexts, international students' view of British students, general public views of people with schizophrenia, and both Muslims' and non-Muslims' views of one another. Among these three intergroup relationships, the role of outgroup contact meta-perceptions was consistently highlighted as predictor of intergroup contact. In stark contrast, ingroup contact metaperceptions did not emerge as a significant predictor of contact. Intergroup contact then predicted outgroup attitudes (Studies 1, 2 and 3) and stereotyping (Studies 2 and 3) via reduced anxiety (Studies 2 and 3). The results demonstrate the importance of explicitly highlighting outgroups' openness for intergroup interactions, and are discussed in the context of intergroup relations literature.
\end{abstract}

KEYWORDS: intergroup contact, meta-perceptions, outgroup attitudes, intergroup anxiety, stereotyping 
Substantial research has focused on how to improve people's attitudes toward outgroups via intergroup contact (Allport, 1954; Hodson \& Hewstone, 2013). Intergroup contact typically reduces intergroup prejudice across a variety of groups, including members of various ethnic groups, LGBT communities, and people with disabilities or mental illness (Pettigrew \& Tropp, 2006; Pettigrew, Tropp, Wagner \& Christ, 2011). Research has also identified processes underlying how and why intergroup contact improves intergroup attitudes, including enhanced knowledge, reduced anxiety, and increased empathy in relation to the outgroup (Pettigrew \& Tropp, 2008).

Thus far, most contact research has considered intergroup contact as the starting point for intergroup relations, when contact can also be conceived of as an outcome of positive intergroup relations (Swart, Hewstone, Christ, \& Voci, 2011) and supportive social norms (Al Ramiah, Schmid, Hewstone, \& Floe, 2015). More research is therefore needed to understand when individuals are more willing to engage in cross-group interactions.

We propose that people's willingness to engage in contact may rely on metaperceptions, or how one expects to be viewed by others, and specifically those metaperceptions pertaining to expectations for intergroup contact. Research has shown that people rely on stereotypes, social norms and values when forming meta-perceptions in intergroup contexts (Sigelman \& Tuch, 1997; see Frey \& Tropp, 2006), and that meta-perceptions often predict intergroup attitudes (Kteily, Hodson, \& Bruneau, 2016; Vorauer, Hunter, Main, \& Roy, 2000). It has also been argued that perceptions about how the outgroup views the ingroup can have harmful consequences on intergroup relations if they are misinformed due to stereotypes or prejudice (Vezzali, 2016).

Although intergroup contact and meta-perceptions play critical roles in predicting intergroup attitudes, we know relatively little about the interplay between the two. Contact meta-perceptions - that is, meta-perceptions regarding the outgroup's desire for contact with 
the ingroup, or the ingroup's desire for contact with the outgroup - have not been distinguished from other group-related meta-perceptions. Doing so is necessary, however, to identify factors that may encourage or hinder contact, and to determine how contact metaperceptions, as well as contact itself, may independently or jointly contribute to predicting intergroup attitudes. In three studies conducted across three distinct intergroup contexts, this research examines how meta-perceptions regarding ingroup and outgroup desire for contact may motivate people to engage in intergroup contact and shape their intergroup attitudes.

\section{Contact Meta-Perceptions Regarding the Ingroup}

Growing from the literature on extended contact (see Wright, Aron, McLaughlinVolpe, \& Ropp, 1997), considerable research suggests that knowing that ingroup members have contact with the outgroup can uniquely predict more positive intergroup attitudes (see Vezzali, Hewstone, Capozza, Giovannini, \& Wolfer, 2014; Zhou, Page-Gould, Aron, Moyer, \& Hewstone, 2019). Such effects likely emerge because knowledge of cross-group contact leads people to perceive more support for contact among ingroup members (e.g., De TezanosPinto, Bratt, \& Brown, 2010; Gomez, Tropp, \& Fernandez, 2011).

Furthermore, knowing that ingroup members have contact with the outgroup can function as a precursor to greater intergroup contact (Pettigrew, Christ, Wagner and Stellmacher, 2007). Vezzali, Stathi, Giovannini, Capozza and Visintin (2015) provided longitudinal support for this notion: their extended contact intervention resulted in a higher number of actual cross-group friendships among Italian school children three months later. Moreover, Gomez et al. (2011) showed that extended contact predicted positive orientations toward future intergroup contact, even when controlling for participants' prior contact experiences. Consistent with this work, we argue that it is not only the knowledge about one's ingroup having intergroup contact, but also the perception regarding the ingroup's desire for contact that can also predict intergroup interactions. In other words, we posit that 
when people perceive fellow ingroup members to desire contact with the outgroup, they will become more likely to engage in contact themselves.

\section{Contact Meta-Perceptions Regarding the Outgroup}

We also contend that contact meta-perceptions regarding the outgroup will play a key role in predicting intergroup contact and attitudes. Studies from several countries show that the more immigrants are perceived to desire contact with the host society, the more members of the host society hold positive attitudes toward them (Matera, Stefanile, \& Brown, 2012; Zagefka, Brown, Broquard, \& Leventoglu Martin, 2007). Relatedly, the more ethnic minority and ethnic majority group members perceived the other group to desire intergroup contact, the more they themselves reported being interested in contact with the other group (Tropp \& Bianchi, 2006).

The importance of perceived outgroup desire for contact receives additional support from research by Shelton and Richeson (2005), who show that racial majority and minority group members may avoid contact with each other due to fear of rejection by the respective outgroup (see also Al Ramiah et al., 2015). Relatedly, White participants who saw images of a Black man with a White friend reported less concern about being rejected by Black people (Shapiro, Baldwin, Williams, \& Trawalter, 2007) and Black participants expected to be seen more favourably and to have more comfortable interactions with a White conversation partner when the White partner was presented as having cross-group friendships (Wout, Murphy, \& Steele, 2010). These findings suggest that the perceived stance of the outgroup can motivate (if positive) or, respectively thwart (if negative) the intention to engage positive intergroup interactions.

\section{Contact Meta-Perceptions Regarding Both the Ingroup and Outgroup}

Together, these bodies of research suggest that perceived outgroup desire to have contact with the ingroup, and perceived ingroup desire to have contact with the outgroup, can 
each be an important predictor of intergroup attitudes. In the present research, we examine both as predictors of contact and attitudes simultaneously. Moreover, through structural equation models, we extend prior work by testing simultaneously the degree to which each may predict intergroup contact, as well as the degree to which these contact metaperceptions, and contact itself, may contribute to predicting intergroup attitudes.

Although here we focus on contact meta-perceptions as antecedents of intergroup contact, we recognize that prior research on extended contact has examined the closely related constructs of ingroup and outgroup norms, showing that norms often mediate the pathways between extended contact and intergroup attitudes (e.g., Cameron et al., 2011; De Tezanos-Pinto et al., 2010; Vezzali et al., 2015). In such studies, measures of norms typically assess how often people think ingroup members or outgroup members interact with each other (descriptive norms), and whether ingroup members or outgroup members would (or would not) approve of relations between groups (injunctive norms). By assessing contact meta-perceptions in the present research, we are asking individuals to generate their own views regarding the stance of ingroup members and outgroup members, rather than asking them to provide estimates based on normative information. Additionally, studies that include norms as potential mediators of extended contact effects typically include assessments of intergroup contact as a statistical control, to show the effects of extended contact beyond any prior contact that individual participants might have experienced; instead, in the present research, we include intergroup contact as a predictor of intergroup attitudes in tandem with measures of contact meta-perceptions, to model the processes and distinct roles each might play in predicting intergroup attitudes.

\section{Overview of the Present Research}

In sum, this research aims to model how contact meta-perceptions and intergroup contact both contribute to predicting intergroup attitudes. When considered simultaneously, 
we expect that ingroup and outgroup contact meta-perceptions will function mostly as proximal predictors of intergroup contact, and that intergroup contact will function as a proximal predictor of intergroup attitudes. We model relations among these variables in relation to three distinct types of intergroup relationships, using data gathered from four samples: international students reporting attitudes toward British people (Study 1), British students reporting attitudes toward people with schizophrenia (Study 2), and Muslims and non-Muslims reporting attitudes toward each other in the UK (Study 3). Across these studies, we cover a broad spectrum of intergroup relationships, while also including samples of participants whose groups vary in status within the broader society. Focusing on both majority and minority group perspectives will enable us to test the generalisability of our predictions and help us further understand intergroup dynamics. We do not have specific hypotheses pertaining to different intergroup relationships; rather, we expect to observe similar patterns of results across studies and groups.

\section{Data Analytic Plan}

In each study, we tested our predictions using structural equation modelling with observed variables (SEM). Model fit was tested using the criteria suggested by $\mathrm{Hu}$ and Bentler (1999; see also Kline, 2010), namely the chi-square test statistic $\left(\chi^{2}\right)$, the comparative fit index (CFI), the root-mean-square error of approximation (RMSEA), and the standardized root-mean-square residual (SRMR). A satisfactory fit is expressed by a CFI value greater than .95 , an RMSEA value smaller or equal to .06, an SRMR smaller or equal to .08 (Hu \& Bentler, 1999), and a $\chi^{2} / d f$ ratio smaller than 3 (Kline, 2010).

Direct effects of the exogenous variables (contact meta-perceptions) and the first level mediator (positive contact, in Study 2 and 3) to all other variables were not estimated in order to avoid a perfect model fit; correlations between variables included at the same level in the models (ingroup and outgroup contact meta-perceptions across all three studies, and outgroup 
attitudes and negative stereotyping in Studies 2 and 3) were estimated. Mediation was tested by using bootstrapping procedures with 5,000 resamples (Hayes, 2013).

\section{Study 1: International University Students}

Study 1 focused on international students at a university in the UK. While international students have chosen to live and study in another country, they often experience personal and social loneliness in the host country (Sawir, Marginson, Deumert, Nyland, \& Ramia, 2008), are likely to socialize with other international students and with students from their homeland as opposed to people from the host country (Sherry, Thomas, \& Chui, 2010; Sigalas, 2010), and sometimes report that interactions with members of the host community are difficult and uncomfortable (Zhang \& Brunton, 2007). Globally, the UK is the second largest host location for international students (UK Council for International Student Affairs, 2018). In this context, we examine how international students' contact meta-perceptions regarding the ingroup (other international students) and outgroup (British students) predict contact with British students, as well as how contact meta-perceptions and contact with British students jointly predict outgroup attitudes (attitudes toward British students).

\section{Method}

\section{Participants and Procedure}

From an initial sample of 94 international students, six were removed due to not disclosing their international status, and two were removed due to stating their nationality as British and English/Malaysian respectively. This left a final sample of 86 participants (63 female, 21 male, 2 unspecified), aged between 18 and 36 years $(M=22.32$ years, $S D=3.40)$, representing a variety of nationalities. Participants were approached individually by research assistants on the university campus and at international student events. All participants provided informed consent and proceeded to complete a questionnaire either online or using a 
paper copy. Following completion of the questionnaire, participants were debriefed and thanked for their participation.

\section{Measures}

Contact meta-perceptions. Contact meta-perceptions were assessed by asking international students three items about the extent to which they perceived British students as desiring contact with international students (outgroup contact meta-perceptions, $\alpha=.92$; e.g., "To what extent do you think that British students want to interact with international students?") and three items about the extent to which they perceived international students as desiring contact with British students (ingroup contact meta-perceptions, $\alpha=.93$; e.g., "To what extent do you think international students want to interact with British students?’). Items were scored on a 5-point scale ranging from 1 (not at all) to 5 (very much).

Intergroup contact. Using items adapted from Voci and Hewstone (2003), participants completed three items concerning the quantity of their contact with British students (e.g., "In everyday life, how frequently do you interact with British students?”; $\alpha=$ .84 ) and five items concerning the quality of their contact with British students (e.g., "unpleasant-pleasant"; $\alpha=.65)$. A composite measure of intergroup contact was created by calculating each participant's average score for contact quantity and quality, and then multiplying these two scores together. This method has proved useful in past research to create an overall index of positive intergroup contact (Stathi \& Crisp, 2010; Voci \& Hewstone, 2003).

Outgroup attitudes. In a single item, participants were asked to report their general attitude toward British students on a thermometer ranging from $0^{\circ}$ (extremely unfavourable) to $100^{\circ}$ (extremely favourable; see Haddock, Zanna, \& Esses, 1993).

\section{Results and Discussion}


Means, standard deviations and correlations for all variables can be found in Table 1. Of particular note, outgroup contact meta-perceptions correlated positively with both intergroup contact and outgroup attitudes, whereas ingroup contact meta-perceptions did not significantly correlate with either of the two variables.

In the hypothesized model, ingroup and outgroup contact meta-perceptions served as exogenous variables, intergroup contact served as the mediator, and outgroup attitudes served as the criterion variable. This initial model showed a poor fit to the data, $\chi^{2}(2)=7.69, p<.05$; $\chi^{2} / d f=3.85 ; \mathrm{CFI}=0.89 ; \mathrm{RMSEA}=.18 ; \mathrm{SRMR}=.07$. Based on correlations reported in Table 1 and on modification indexes proposed for the model, the relation between outgroup contact meta-perceptions and outgroup attitudes was estimated $(\mathrm{MI}=7.34)$. The new model presented an excellent fit to the data, $\chi^{2}(1)=0.01, p=.91 ; \chi^{2} / d f \approx 0.00 ; \mathrm{CFI}=1.00 ;$ RMSEA $\approx .00 ; \mathrm{SRMR} \approx .00$. As shown in Figure 1, outgroup contact meta-perceptions was associated with both intergroup contact and outgroup attitudes; in addition, intergroup contact was directly associated with outgroup attitudes.

In line with hypotheses, bootstrapping estimates (based on 5,000 bootstrap samples) indicated a significant indirect effect of perceived outgroup contact meta-perceptions on outgroup attitudes via greater intergroup contact [point estimate $=2.99, \mathrm{CI}: 1.4541,5.2371$ ] At the same time, while perceived outgroup contact meta-perceptions emerged as a key predictor of contact with British students, perceived ingroup contact meta-perceptions was largely irrelevant. Furthermore, replicating much of the contact literature, positive contact with British students held a strong and positive relationship with outgroup attitudes.

\section{Study 2: Views of People with Schizophrenia}

Results from Study 1 indicate that contact meta-perceptions, and in particular those regarding the outgroup, predict intergroup contact and outgroup attitudes. We sought to replicate and extend this first study by examining how contact meta-perceptions and 
intergroup contact itself might predict attitudes toward people with schizophrenia. Negative attitudes toward people with mental health issues are widespread (Corrigan, 2006), with schizophrenia eliciting particularly negative stereotypes (Wood, Birtel, Alsawi, Pyle, \& Morrison, 2014). Prior research has also suggested that attitudes toward people with mental health issues are closely linked to feelings of uneasiness, fear, anxiety, and uncertainty (Angermeyer \& Dietrich, 2006).

Exploring the role of contact meta-perceptions in the context of attitudes toward people with schizophrenia provides a useful extension to model testing from Study 1, while also suggesting additional variables that might be relevant to consider. Specifically, along with outgroup attitudes, we included outgroup stereotypes as a second criterion variable, given the severe stigmatization of people with schizophrenia (Wood et al., 2014). We also included a measures of intergroup anxiety (see Stephan \& Stephan, 1985), because attitudes toward people with mental health issues are often tied to feelings of anxiety (Angermeyer \& Dietrich, 2006) and intergroup anxiety has been shown to mediate the relation between intergroup contact and outgroup attitudes (Pettigrew \& Tropp, 2008).

\section{Method}

\section{Participants and Procedure}

From an initial sample of 123 participants, six were removed due to missing responses ( $>20 \%$ of the total items). Thus, 117 people were included in the final study ( 72 female, 41 male, 4 unspecified), aged between 18 and 67 years $(M=30.53$ years, $S D=13.10)$. Participants were recruited either through the university's student research participation scheme or were invited to participate on an individual basis via university and community email distribution lists. Participants recruited through the research participation scheme received course credit for their participation, and the remaining participants were given the opportunity to enter a prize draw for two $£ 25$ Amazon vouchers. All participants were 
provided with a brief explanation of the study and indicated informed consent before completing an online questionnaire; after completing the online questionnaire, participants were thanked and debriefed.

\section{Measures}

Contact meta-perceptions. Measures used to assess contact meta-perceptions were identical to those used as in Study 1, except that items assessing ingroup contact metaperceptions asked about the perceived desire of people without mental health issues to have contact with people with schizophrenia $(\alpha=.78)$, and items assessing outgroup contact metaperceptions asked about the perceived desire of people with schizophrenia to have with people without mental health issues $(\alpha=.85)$.

Intergroup contact. As in Study 1, a composite measure of intergroup contact was created (see Voci \& Hewstone, 2003) by multiplying measures of contact quantity $(\alpha=.95)$ and quality $(\alpha=.69)$, using items that asked participants about their contact with people with schizophrenia.

Intergroup anxiety. To assess intergroup anxiety, participants were asked to rate the extent to which they feel each of seven emotions when interacting with people with schizophrenia (e.g., anxious, suspicious; $\alpha=.87$ ). Item responses ranged from 1 (not at all) to 7 (very much; see Stephan \& Stephan, 1985).

Outgroup attitudes. Using items adapted from the self-report inventory of Fear and Behavioural Intentions toward the mentally ill (Svensson et al., 2011), participants were asked to report their attitudes toward the outgroup in 10 items (e.g., "I would be willing to work with somebody with schizophrenia"; $\alpha=.90)$. Responses were scored on a 5-point scale ranging from 1 (very unlikely) to 5 (very likely).

Negative stereotypes. An adaptation of Stathi, Tsantila and Crisp's (2012) 13-item scale was used to assess the extent to which participants held negatively stereotypes about 
people with schizophrenia (e.g. unpredictable, dangerous; $\alpha=.89$ ) Responses were scored on a 7-point scale ranging from 1 (not at all) to 7 (very much).

\section{Results and Discussion}

Means, standard deviations and correlations for all variables are provided in Table 2. Of note, we found that outgroup contact meta-perceptions correlated positively with contact and outgroup attitudes, and negatively with intergroup anxiety and stereotyping. There was also a marginal negative correlation between ingroup contact meta-perceptions and stereotyping as well as intergroup anxiety, and a positive correlation with outgroup attitudes.

In Study 2, we tested a model in which ingroup and outgroup contact metaperceptions served as the exogenous variables, intergroup contact served as the first level mediator, intergroup anxiety as the second level mediator, and outgroup attitudes and negative stereotypes were the criterion variables. This model presented a poor fit to the data, $\chi^{2}(8)=35.60, p<.001 ; \chi^{2} / d f=0.59 ; ; \chi^{2} / d f=4.45 ; \mathrm{CFI}=.91 ; \operatorname{RMSEA}=.15 ; \operatorname{SRMR}=.14$ To improve the model fit, further path estimation was determined by considering both modification indexes and correlations. Since the correlations between the exogenous variables with the second level mediator and with the dependent variables, along with the correlations between the first level mediator with the dependent variables, were significant (see Table 2), the procedure suggested by Bollen (1989) was employed. For each single parameter, we tested whether its estimate would have produced a significant decrease of the $\chi 2$ statistic. From this analysis, it emerged that the paths from meta-perceptions to anxiety were estimated $(\mathrm{MI}>6.68)$ along with the path from meta-perceptions to outgroup attitudes $(\mathrm{MI}>3.29)$ and produced a significant improvement of the $\chi 2, \Delta \chi 2 \mathrm{~s}(1)>7.73, p<.01$; regarding the remaining paths (i.e., from contact to the dependent variables) no significant decrease of the $\chi 2$ was observed, $\Delta \chi 2 \mathrm{~s}(1)<1.97$, ns. The new model presented an excellent adaptation to the data, $\chi 2(4)=2.80, \mathrm{p}=.59 ; \chi 2 / \mathrm{df}=0.70 ; \mathrm{CFI}=1.00 ; \mathrm{RMSEA} \approx .00 ; \mathrm{SRMR}$ 
$=.02$. As can be seen in Figure 2, similar to Study 1, outgroup, but not ingroup, metaperceptions were associated with intergroup contact; both meta-perceptions were negatively related with anxiety; in addition, outgroup, but not ingroup, meta-perceptions positively associated with attitudes. Regarding the mediators, intergroup contact was associated with decreased anxiety that, in turn, was related to more negative stereotypes and less positive outgroup attitudes.

Bootstrapping analyses with 5,000 resamples (see Table 3) confirmed that all the indirect paths were significant. Outgroup contact meta-perceptions was indirectly linked to outgroup attitudes and negative stereotypes via intergroup contact and anxiety, and via anxiety); on the other hand, ingroup contact meta-perceptions was associated with outgroup attitudes and negative stereotypes only via anxiety.

Replicating the findings of Study 1 in reference to a different intergroup relationship, we observed that perceived outgroup contact meta-perceptions predicted both greater contact with people with schizophrenia, and more positive attitudes toward people with schizophrenia, whereas perceived ingroup contact meta-perceptions did not. However, ingroup contact meta-perceptions predicted intergroup anxiety.

\section{Study 3: Relations Between Muslims and Non-Muslims}

To extend this research further we investigated relations among the same variables in a more challenging and hostile intergroup context—namely, relations between Muslims and non-Muslims in the UK. Relations between Muslims and non-Muslims have been tense, and anti-Muslim attitudes widespread, in many Western societies (Pew Research Center, 2015; Verkuyten, 2007), and the UK is no exception. Data from numerous European countries also suggest that levels of anti-Muslim prejudice tend to be higher than more general prejudices against immigrants (Strabac \& Listhaug, 2008). Thus, in Study 3 we sought to replicate the findings of the previous two studies in this more challenging intergroup context, while also 
considering how contact meta-perceptions and intergroup contact predict anxiety, outgroup attitudes, and negative stereotypes from the perspectives of both groups in the intergroup relationship, i.e. Muslims and non-Muslims.

\section{Method}

\section{Participants and Procedure}

Participants were recruited by a research assistant via an online participant pool (Prolific Academic) or from university and community email distribution lists. With respect to the Muslim sample, from an initial sample of 117 participants, 17 were removed from the sample due to not providing the relevant religious affiliation. This left a final sample of 100 Muslim participants (50 female, 49 male, 1 unspecified) aged between 18 and 74 years $(M=$ 26.39 years, $S D=9.30$ ). The non-Muslim sample consisted of 120 non-Muslim participants living in the UK (64 female, 53 male, 1 agender, 2 unspecified) aged between 18 and 67 years $(M=30.63, S D=10.41)$. Those recruited through the online pool received $£ 1$ for their participation, whilst the remaining participants were given the option to enter a prize draw for two $£ 25$ Amazon vouchers. All participants completed an online questionnaire, which comprised of an informed consent form, the measures used in this study, and the debrief form.

\section{Measures}

Contact meta-perceptions. Measures used to assess contact meta-perceptions were identical to those used as in Studies 1 and 2, except that items were adapted for the present context. Specifically, items used to assess outgroup contact meta-perceptions asked about the perceived desire of non-Muslims for contact with Muslims in the Muslim sample $(\alpha=.85)$ and vice versa in the non-Muslim sample $(\alpha=.93)$; items used to assess ingroup contact meta-perceptions asked about the perceived desire of Muslims for contact with non-Muslims in the Muslim sample $(\alpha=.92)$ and vice versa in the non-Muslim sample $(\alpha=.87)$. 
Intergroup contact. As in Study 2, both the quantity (Voci \& Hewstone, 2003, three items, e.g. "How many Muslims/non-Muslims do you know?" 1 = none, 7 = a lot; Muslim $\alpha$ $=.64$, non-Muslim $\alpha=.81$ ) and quality of contact (Ortiz \& Harwood, 2007; five items, e.g. "How close do you feel to Muslims/non-Muslims?" 1 = not at all close/not at all, 5 = very close/very much; Muslim sample $\alpha=.92$, non-Muslim sample $\alpha=.89$ ) Muslim and nonMuslim participants had with the other group was measured. As in Study 2, a composite measure of intergroup contact was created by multiplying each participant's mean score for contact quantity and quality (Voci \& Hewstone, 2003).

Intergroup anxiety. The same measure of intergroup anxiety was used as in Study 2 (Stephan \& Stephan, 1985), with Muslims and non-Muslims indicating the extent to which they felt anxious when interacting with members of the other group (Muslim sample $\alpha=.82$, non-Muslim sample $\alpha=.86$ ).

Social distance. As an alternative to the measures of outgroup attitudes used in Studies 1 and 2, and to strengthen the replication of the results obtained in Studies 1 and 2, a different measure of outgroup attitudes was employed in Study 3. In line with literature on social distance (Bogardus, 1933), four items asked about how the participant would feel about having an outgroup member as a "friend", "neighbour", "boss" or as a "family member" (for Muslims $\alpha=.83$, non-Muslims $\alpha=.92$ ). Responses were scored on a 5-point scale, ranging from 1 (definitely would not mind) to 5 (definitely would mind).

Negative stereotypes. The extent to which Muslim and non-Muslim participants negatively stereotyped the other group was assessed using Gonzalez, Verkuyten, Weesie and Poppe's (2008) stereotyping scale. To assess negative stereotypes, participants indicated the extent to which they perceived eight negative characteristics as describing the other group (e.g. dishonest, inferior; for Muslims $\alpha=.89$, non-Muslims $\alpha=.86$ ). Item responses were scored on a 5-point scale ranging from 1 (not at all) to 5 (very much). 


\section{Results and Discussion}

Means, standard deviations and correlations for all variables can be found in Tables 4 and 5 (for Muslim and non-Muslim samples, respectively). Outgroup and ingroup contact meta-perceptions correlated positively with contact, and negatively with intergroup anxiety, social distance, and stereotyping, in both the Muslim and non-Muslim samples. As in Study 2, we run the serial mediation model for the Muslim and non-Muslim sample separately, with perceived ingroup and outgroup desire for contact as exogenous variables, positive contact as first level mediator, anxiety as second level mediator, and social distance and negative stereotypes as dependent variables.

\section{Muslim sample}

As with the previous studies, goodness-of-fit indexes indicated a poor fit of the model to the data, $\chi^{2}(8)=40.43, p<.001 ; \chi^{2} / d f=5.05 ; \mathrm{CFI}=0.91 ; \operatorname{RMSEA}=.17 ; \operatorname{SRMR}=.15$. Analysing correlations and modification indexes, it emerged that, to ameliorate the model fit, the direct paths from meta-perceptions to both anxiety and stereotypes should be estimated $(M I>4.34)$, along with the path from contact to stereotypes $(M I=4.68)$. In fact, from the $\chi^{2}$ difference test, it emerged that estimating the latter coefficients significantly reduced the $\chi^{2}$ statistic, $\Delta \chi^{2} \mathrm{~s}(1)>5.07, p<.05$; conversely, for the remaining paths the difference was nonsignificant, $\Delta \chi^{2} \mathrm{~s}(1)<1.01, n s$.

The new model presented a good fit to the data, $\chi^{2}(3)=2.31, p=.51 ; \chi^{2} / d f=1.62 ;$ CFI $=1.00 ; \mathrm{RMSEA} \approx .00 ; \mathrm{SRMR}=.03$. Figure 3 shows that outgroup contact meta-perceptions were associated with higher contact and less stereotyping; on the other hand, ingroup contact meta-perceptions were negatively related with both anxiety and stereotypes. In turn, contact was negatively associated with anxiety and anxiety was related to increased social distance and stereotyping. Finally, contact was negatively associated with decreased stereotyping. In 
Table 6, results from the bootstrapping analyses reported that all the mediated paths were significant.

\section{Non-Muslim sample}

The model presented a poor fit to the data, $\chi^{2}(8)=44.98, p<.001 ; \chi^{2} / d f=5.62 ; \mathrm{CFI}=$ $.91 ;$ RMSEA $=.18 ;$ SRMR $=.16$. As with the Muslim sample (and Study 2 ), by analyzing correlations and modifications indexes, the model fit was improved. The estimation of the direct relations from outgroup meta-perceptions to both anxiety and stereotypes (MI > 8.12), along with the association between ingroup meta-perceptions and anxiety $(\mathrm{MI}=9.78)$, enhanced the fit indexes, $\Delta \chi^{2}(1)>8.41, p<.01$; on the other hand, for the other associations, the latter difference was not significant, $\Delta \chi^{2}(1)>2.01, n s$.

The new model, presented in Figure 4, presented an excellent fit to the data, $\chi^{2}(5)=$ $1.50, p=.91 ; \chi^{2} / d f=0.30 ; \mathrm{CFI}=1.00 ; \mathrm{RMSEA} \approx .00 ; \mathrm{SRMR}=.02$. As can be seen from the figure, outgroup contact meta-perceptions were positively related with contact, and negatively related with intergroup anxiety and stereotyping. In addition, contact was associated with reduced anxiety that, in turn, had positive associations with social distance and with negative stereotyping. ${ }^{1}$

Bootstrapping results are provided in Table 6 . As can be noted, only outgroup perceptions were indirectly (and directly) related with the dependent variables through the double mediation (i.e., via positive contact and anxiety) and via the indirect effect of decreased anxiety.

The results of Study 3 again provided support for the importance of contact metaperceptions on positive intergroup contact and attitudes. The pattern of results was quite similar for both Muslims and non-Muslims (see also Footnote 1). In both groups, when considered as simultaneous predictors, outgroup but not ingroup, contact meta-perceptions predicted positive contact. This was then linked to the mediational pathway to improved 
attitudes (that is, lower social distance and stereotyping via reduced anxiety). As with Study 2, ingroup contact meta-perceptions were associated with lower anxiety in the case of Muslims only.

\section{General Discussion}

The present research examined the role of contact meta-perceptions regarding the ingroup's and outgroup's desire to interact with one another on positive contact and, subsequently, attitudes. We investigated this in a number of distinct intergroup relationships, focusing on the perspective of international university students and their relationship with British students, the perceptions of the general public toward people with schizophrenia, and the relationship between Muslims and non-Muslims in the UK. The role of perceived outgroup desire for contact was consistently highlighted across the three studies. This is, to our knowledge, the first time that contact meta-perceptions were singled out from the larger array of intergroup meta-perceptions, and were tested as a predictor of contact and attitudes. In our research perceptions regarding the outgroup's desire for contact has been explicitly studied in conjunction with the ingroup's desire for contact. We argue that having considered several intergroup relationships, from the point of view of majority and minority members, adds confidence to our findings.

Our results are in line with previous research, which has highlighted the benefits of positive perceptions regarding the outgroup's behaviour and attitudes (Matera et al., 2012; Tropp \& Bianchi, 2006). Tangentially, our results are also in line with research that highlights the importance of positive intergroup expectations on the path from quality of contact to positive outgroup attitudes (Deegan, Hehman, Gaertner, \& Dovidio, 2015).

Unexpectedly, in stark contrast to our findings regarding outgroup contact metaperceptions, ingroup contact meta-perceptions did not predict positive contact in any of the three studies when tested against each other (despite being correlated with contact in Studies 
2 and 3). In Study 2 and 3 (for the Muslim sample only), however, ingroup contact metaperceptions predicted lower intergroup anxiety. This finding demonstrates the importance of ingroup contact meta-perceptions on this key affective factor that is closely associated with intergroup attitudes.

The concept of perceived ingroup desire for contact could be linked to the extended contact theory (Wright et al., 1997). Extended contact theory would argue that, contrary to our findings, perceived ingroup desire for contact should be positively related to intergroup contact. However, a key difference between the context proposed in the extended contact theory and the present research is whether an individual's ingroup members are actually taking part in intergroup contact, or if they are merely perceived as wanting said contact. This subtle yet important difference could account for the lack of a significant predictive relationship found across the three intergroup contexts between perceived ingroup desire and the individual's positive intergroup contact. In fact, even if the individual believes that the ingroup wants contact, what may be more relevant is seeing such contact taking place (see extended and vicarious contact literature); if this does not happen, then engaging in contact could be considered counter-normative. Supporting the key role of perceptions, research (Gomez, Tropp, Vázquez, Voci, \& Hewstone, 2018) and meta-analytic evidence (Zhou et al., 2019) on contact literature and specifically on extended contact has shown that it is perceived (rather than actual) extended contact that is particularly effective in improving intergroup attitudes.

Despite speculating on why ingroup contact meta-perceptions did not emerge as a stronger predictor of contact and attitudes in our research, we do not currently have evidence to support our speculations. However, the role of perceptions regarding the ingroup stance on intergroup relations has been highlighted in the contact (e.g., Al-Ramiah et al., 2015; Shelton \& Richeson, 2005; Wright et al., 1997) and self-categorisation (e.g., Hogg \& Turner, 1987) 
literature. Therefore, further research is necessary to establish why, or under which conditions, although associated with contact and attitudes, perceiving that the ingroup desires contact with the outgroup has weaker (or no) predictive power when tested against outgroup contact meta-perceptions. Disentangling contact meta-perceptions can further assist our understanding of resegregation and contact avoidance in intergroup contexts (Al-Ramiah et al., 2015).

Our results discussed thus far have provided an interesting insight into the role of contact meta-perceptions, suggesting that positive intergroup contact is strongly related to the perception that the outgroup wants this intergroup contact to occur, yet in contrast appears unrelated to the perception that fellow ingroup members want such contact. The crucial role of perceptions regarding the outgroup's willingness to engage in intergroup interactions can be explained via research that points to important deterrents of contact, namely fear of being rejected by the outgroup and perceptions that its members are not interested in intergroup interactions (Shapiro et al., 2007; Shelton \& Richeson, 2005). According to our findings, the perception that the outgroup in fact wants to interact with the ingroup may determine people's subsequent intergroup contact experiences, although the correlational nature of our research does not allow us to make firm conclusions as to the direction of causality between these variables of interest.

We note that our measures of contact meta-perceptions focused on perceived willingness/desire to engage in contact with the outgroup. This is in line with research that suggests that interest in contact is fundamental in predicting contact behaviours (e.g., Al Ramiah et al., 2015); and with research that shows that intention is the most proximal predictor of behaviour (Ajzen, 1985). We did not assess other perceived dimensions of contact, such as quality and valence. Current research demonstrated that people spontaneously imagine contact situations and it is predominantly the quality of such imagined 
interactions that drives attitudes and intended behaviour (Stathi, Guerra, Di Bernardo, \& Vezzali, 2019). As such, individuals who perceive that the ingroup and/or the outgroup expect to have negative, low quality contact may be less inclined to interact with the outgroup (due to, for example, increased intergroup anxiety). Future research can shed further light on this.

Previous research has highlighted norms as a predictor of intergroup attitudes (e.g., De Tezanos-Pinto et al., 2011). We suggest that contact meta-perceptions are a related but different construct that reflects a more individual and subjective appraisal of social situations. It is plausible, for example, that social norms precede and affect the formation of metaperceptions. Research to date, to the best of our knowledge, has not directly distinguished between norms and (meta)-perceptions as predictors of attitudes and behaviour, so this can be further clarified in the future.

We acknowledge that an important limitation of the present research is the correlational nature of the results that does not allow inferences regarding causality between the variables. We provide, however, preliminary evidence for the significant role of outgroup contact meta-perceptions when attempting to understand the predictors of positive intergroup contact. There is a clear need for experimental as well as longitudinal research to further investigate contact meta-perceptions as a predictor of positive contact. Moreover, we can only be speculative as to why this consistent relationship between outgroup contact metaperceptions and intergroup contact occurred; the results reported here do not provide a sufficient explanation as to why this variable is more important than ingroup contact metaperceptions, with further research needed to clarify this.

It should also be noted that our samples had a fairly small size, which suggests that caution should being taken when interpreting the results. However, the replication of the key findings (namely the relations between outgroup contact meta-perceptions, contact and 
attitudes) across three studies and four different samples help to ameliorate this sample size issue. Additionally, across all the studies, we recruited participants in order to reach power of at least 0.8 to detect a small effect size, and with the aim of conducting a mediation analysis in which bias-corrected bootstrapped estimates were employed for testing indirect effects (MacKinnon, Lockwood, \& Williams, 2004). We also acknowledge that despite using established measures of contact quality and quantity, our measures did not, on some occasions, have high reliability. The modest alpha coefficients need to be taken into consideration when interpreting the results. Additionally, in Study 2 we did not collect information regarding participants' mental health. We need to note this as a limitation, as it is possible that some participants may have experienced mental health issues themselves, which could have -to an extent- affected their responses.

Understanding the interplay between contact meta-perceptions and engaging in intergroup contact can allow us to encourage and facilitate interactions between groups. Our research can be the starting point for methods of promoting contact by finding ways to demonstrate the groups' openness and desire to interact with other groups. Considering our findings, we suggest that it is particularly important to highlight the desire of the outgroup to have contact with the ingroup. This could be done, for example, via interventions that demonstrate that the outgroup is willing and keen to have engage in meaningful contact with the ingroup. With the addition of further experimental and longitudinal research, this area of research can be particularly useful in intergroup contexts characterized by segregation and low existing levels of positive intergroup contact. 


\section{$\underline{\text { Footnote }}$}

1. In a further analysis, differences between Muslim and non-Muslim samples were investigated. Specifically, a multiple group analysis was employed. First, a model where path coefficients were allowed to be freely estimated was compared with a model where all coefficients were constrained to be equal; then, these two models were compared by using the chi-square difference test. The fit of the unconstrained model was good, $\chi^{2}(6)=3.68, p=.72$; $\chi^{2} / d f=5.62 ; \mathrm{CFI}=1.00 ; \mathrm{RMSEA} \approx .00 ; \mathrm{SRMR}=.02$. The model with constrained path produced a significant drop of model fit, $\Delta \chi^{2}(18)=33.83, p<.05$. Specifically, differences emerged considering the paths from outgroup and ingroup meta-perceptions to anxiety, $\Delta \chi^{2} \mathrm{~s}(1)<4.39, p<.05$; no others significant differences emerged. 


\section{References}

Allport, G. W. (1954). The nature of prejudice. New York, NY: Addison-Wesley.

Angermeyer, M. C., \& Dietrich, S. (2006). Public beliefs about and attitudes towards people with mental illness: A review of population studies. Acta Psychiatrica Scandinavica, 113, 163-179. doi: 10.1111/j.1600-0447.2005.00699.x

Ajzen, I., (1985). From intentions to actions: a theory of planned behavior. In: Kuhl, J., \& Beckman, J. (Eds.), Action-control: From cognition to behavior (pp. 11-39). Springer, Heidelberg.

Bogardus, E. S. (1933). A social distance scale. Sociology and Social Research, 17, 265-271.

Bollen, K. A. (1989). Structural equations with latent variables. New York: Wiley.

Cameron, L., Rutland, A., Hossain, R., \& Petley, R. (2011). When and why does extended contact work? The role of high quality direct contact and group norms in the development of positive ethnic intergroup attitudes amongst children. Group Processes and Intergroup Relations, 14, 193-206. https://doi.org/10.1177/1368430210390535

Cialdini, R.B., \& Goldstein, N.J. (2004). Social influence: Compliance and conformity. Annual Review of Psychology, 55, 591-622. https://doi.org/10.1146/annurev.psych.55.090902.142015

De Tezanos-Pinto, P., Bratt, C. \& Brown, R. (2010). What will the others think? In-group norms as a mediator of the effects of intergroup contact. British Journal of Social Psychology, 49, 507-523. doi: 10.1348/014466609X471020

Deegan, M. P., Hehman, E., Gaertner, S. L., \& Dovidio, J. F. (2015). Positive expectations encourage generalization from a positive intergroup interaction to outgroup attitudes. Personality and Social Psychology Bulletin, 41, 52-65.

https://doi.org/10.1177/0146167214556240 
Frey, F. E., \& Tropp, L. R. (2006). Being seen as individuals versus as group members: Extending research on metaperception to intergroup contexts. Personality and Social Psychology Review, 10, 265-280. https://doi.org/10.1207/s15327957pspr1003_5

Gomez, A., Tropp, L. R., \& Fernandez, S. (2011). When extended contact opens the door to future contact: Testing the effects of extended contact on attitudes and intergroup expectancies in majority and minority groups. Group Processes and Intergroup Relations, 14, 161-173. https://doi.org/10.1177/1368430210391119

Gómez, A., Tropp, L. R., Vázquez, A., Voci, A., \& Hewstone, M. (2018). Depersonalized extended contact and injunctive norms about cross-group friendship impact intergroup orientations. Journal of Experimental Social Psychology, 76, 356-370. doi:10.1016/j.jesp.2018.02.010

Gonzalez, K. V., Verkuyten, M., Weesie, J., \& Poppe, E. (2008). Prejudice towards Muslims in the Netherlands: Testing integrated threat theory. British Journal of Social Psychology, 47, 667-685. doi:10.1348/014466608X284443

Haddock, G., Zanna, M. P., \& Esses, V. M. (1993). Assessing the structure of prejudicial attitudes: The case of attitudes toward homosexuals. Journal of Personality and Social Psychology, 65, 1105-1118. http://dx.doi.org/10.1037/0022-3514.65.6.1105

Hayes, A. F. (2013). Introduction to mediation, moderation, and conditional process analysis: A regression-based approach. New York, NY: Guilford Press

Hodson, G., \& Hewstone, M. (Eds.). (2013). Advances in intergroup contact. New York, NY: Psychology Press.

Hu, L., \& Bentler, P. M. (1999). Cutoff criteria for fit indexes in covariance structure analysis: Conventional criteria versus new alternatives. Structural Equation Modeling, 6, 1-55. doi:10.1080/10705519909540118 
Kline, R. B. (2010). Principles and practice of structural equation modeling (3rd ed.). New York: Guilford.

Kteily, N., Hodson, G., \& Bruneau, E. (2016). They see us as less than human: Metadehumanization predicts intergroup conflict via reciprocal dehumanization. Journal of Personality and Social Psychology, 110, 343-370. http://dx.doi.org/10.1037/pspa0000044

MacKinnon, D. P., Lockwood, C. M., \& Williams, J. (2004). Confidence limits for the indirect effect: Distribution of the product and resampling methods. Multivariate Behavioral Research, 39, 99-128. http://dx.doi.org/10.1207/s15327906mbr3901_4

Matera, C., Stefanile, C., \& Brown, R. (2012). Host culture adoption or intercultural contact? Comparing different acculturation conceptualizations and their effects on host members' attitudes towards immigrants. International Journal of Intercultural Relations, 36, 459-471. http://dx.doi.org/10.1016/j.ijintrel.2012.03.002

Ortiz, M., \& Harwood, J. (2007). A social cognitive theory approach to the effects of mediated intergroup contact on intergroup attitudes. Journal of Broadcasting \& Electronic Media, 54, 615-631. http://dx.doi.org/10.1080/08838150701626487

Pettigrew, T. F., Christ, O., Wagner, U., \& Stellmacher, J. (2007). Direct and indirect intergroup contact effects on prejudice: A normative interpretation. International Journal of Intercultural Relations, 31, 411- 425. http://dx.doi.org/10.1016/j.ijintrel.2006.11.003

Pettigrew, T. F., \& Tropp, L. R. (2006). A meta-analytic test of intergroup contact theory. Journal of Personality and Social Psychology, 90, 751-783. http://dx.doi.org/10.1037/0022-3514.90.5.751 
Pettigrew, T. F., \& Tropp, L. R. (2008). How does intergroup contact reduce prejudice? Meta-analytic tests of three mediators. European Journal of Social Psychology, 38, 922-934. doi: 10.1002/ejsp.504

Pettigrew, T. F., Tropp, L. R., Wagner, U., \& Christ, O. (2011). Recent advances in intergroup contact theory. International Journal of Intercultural Relations, 35, 271-280. doi: 10.1016/j.ijintrel.2011.03.001

Pew Global Attitudes Project. (2015, July). Extremism concerns growing in West and predominantly Muslim countries. Retrieved from http/www.pewglobal.org/2015/07/16/extremism-concerns-growing-in-west-andpredominantly-muslim-countries/

Sawir, E., Marginson, S., Deumert, A., Nyland, C., \& Ramia, G. (2008). Loneliness and international students: An Australian study. Journal of Studies in International Education, 12, 148-180. https://doi.org/10.1177/1028315307299699

Shapiro, J. R., Baldwin, M., Williams, A. M., \& Trawalter, S. (2011). The company you keep: Fear of rejection in intergroup interaction. Journal of Experimental Social Psychology, 47, 221-227. doi: 10.1016/j.jesp .2010.10.006

Shelton, J. N., \& Richeson, J. A. (2005). Intergroup contact and pluralistic ignorance. Journal of Personality and Social Psychology, 88, 91-107. http://dx.doi.org/10.1037/00223514.88 .1 .91

Sherry, M., Thomas, P., \& Chui, W. (2010). International students: a vulnerable student population. Higher Education, 60, 33-46. doi: 10.1007/s10734-009-9284-z

Sigalas, E. (2010). Cross-border mobility and European identity: The effectiveness of intergroup contact during the Erasmus year abroad. European Union Politics, 11, 241265. doi: $10.1177 / 1465116510363656$ 
Sigelman, L., \& Tuch, S. A. (1997). Metastereotypes: Blacks’ Perceptions of Whites' Stereotypes of Blacks. Public Opinion Quarterly, 61, 87-101.

Stathi, S., \& Crisp, R. J. (2010). Intergroup contact and the projection of positivity. International Journal of Intercultural Relations, 34, 580-591. http://dx.doi.org/10.1016/j.ijintrel.2010.04.002

Stathi, S., Tsantila, K., \& Crisp, R. J. (2012). Imagining intergroup contact can combat mental health stigma by reducing anxiety, avoidance and negative stereotyping. Journal of Social Psychology, 152, 746-757. http://dx.doi.org/10.1080/00224545.2012.697080

Stephan, W. G., \& Stephan, C. (1985). Intergroup anxiety. Journal of Social Issues, 41, 157176. doi: $10.1111 / \mathrm{j} .1540-4560.1985 . t b 01134 . x$

Strabac, Z., \& Listhaug, O. (2008). Anti-Muslim prejudice in Europe: A multilevel analysis of survey data from 30 countries. Social Science Research, 37, 268-286. http://dx.doi.org/10.1016/j.ssresearch.2007.02.004

Svensson, B., Markström, U., Bejerholm, U., Björkman, T., Brunt, D., Eklund, M., . . .

Sandlund, M. (2011). Test-retest reliability of two instruments for measuring public attitudes towards persons with mental illness. BMC Psychiatry, 11, 11. https://doi.org/10.1186/1471-244X-11-11

Stathi, S., Guerra, R., Di Bernardo, G. A., \& Vezzali, L. (2019). Spontaneous imagined contact and intergroup relations: Quality matters. European Journal of Social Psychology. https://doi.org/10.1002/ejsp.2600

Tropp, L. R., \& Bianchi, R. A. (2006). Valuing diversity and interest in intergroup Contact. Journal of Social Issues, 62, 533-551. doi: 10.1111/j.1540-4560.2006.00472.x

UK Council for International Student Affairs (2018). International student statistics: UK higher education. Retrieved from https://www.ukcisa.org.uk/Research-$\underline{\text { Policy/Statistics/International-student-statistics-UK-higher-education }}$ 
Voci, A., \& Hewstone, M. (2003). Intergroup contact and prejudice towards immigrants in Italy: The mediational role of anxiety and the moderational role of group salience. Group Processes and Intergroup Relations, 6, 37-54. doi: $10.1177 / 1368430203006001011$

Verkuyten, M. (2007). Religious group identification and interreligious relations: A study among Turkish-Dutch Muslims. Group Processes \& Intergroup Relations, 3, 341-357. doi: $10.1177 / 1368430207078695$

Vezzali, V. (2016). Valence matters: Positive meta-stereotypes and interethnic interactions. The Journal of Social Psychology, 157, 247-261. http://dx.doi.org/10.1080/00224545.2016.1208140

Vezzali, L., Hewstone, M., Capozza, D., Giovannini, D., \& Wolfer, R. (2014). Improving intergroup relations with extended and vicarious forms of indirect contact. European Review of Social Psychology, 25, 314-389. doi: 10.1080/10463283.2014.982948

Vezzali, L., Stathi, S., Giovannini, D., Capozza, D., \& Visintin E. P. (2015). And the best essay is...': Extended contact and cross-group friendships at school. British Journal of Social Psychology, 54, 601-615. doi: 10.1111/bjso.12110

Vorauer, J. D., Hunter, A. J., Main, K. J., \& Roy, S. (2000). Meta-stereotype activation: Evidence from indirect measures for specific evaluative concerns experienced by members of dominant groups in intergroup interaction. Journal of Personality and Social Psychology, 78, 690-707. http://dx.doi.org/10.1037/0022-3514.78.4.690

Wood, L., Birtel, M., Alsawy, S., Pyle, M., \& Morrison, A. (2014) Public perceptions of stigma towards people with schizophrenia, depression, and anxiety. Psychiatry Research, 220, 604-608. http://dx.doi.org/10.1016/j.psychres.2014.07.012

Wout, D. A., Murphy, M. C., \& Steele, C. M. (2010). When your friends matter: The effect of White students' racial friendship networks on meta-perceptions and perceived 
identity contingencies. Journal of Experimental Social Psychology, 46, 1035-1041. https://doi.org/10.1016/j.jesp.2010.06.003

Wright, S. C., Aron, A., McLaughlin-Volpe, T., \& Ropp, S. A. (1997). The extended contact effect: Knowledge of cross-group friendships and prejudice. Journal of Personality and Social Psychology, 73, 73-90. doi: 10.1037/0022-3514.73.1.73

Zagefka, H., Brown, R., Broquard, M., \& Leventoglu Martin, S. L. (2007). Predictors and consequences of negative attitudes toward immigrants in Belgium and Turkey: The role of acculturation preferences and economic competition. British Journal of Social Psychology, 46, 153-169. doi: 10.1348/014466606X111185

Zhou, S., Page-Gould, E., Aron, A., Moyer, A., \& Hewstone, M. (2019). The extended contact hypothesis: A meta-analysis on 20 years of research. Personality and Social Psychology Review, 23, 132-160. doi:10.1177/1088868318762647

Zhang, Z., \& Brunton, M. (2007). Differences in living and learning: Chinese international students in New Zealand. Journal of Studies in International Education, 11, 124-140. https://doi.org/10.1177/1028315306289834 
Table 1. Descriptive Statistics and Correlations between Variables, Study $1(N=86)$

\begin{tabular}{|c|c|c|c|c|c|c|c|c|}
\hline Variable & Mean & $\mathrm{SD}$ & 1 & 2 & 3 & 4 & 5 & 6 \\
\hline 1. Outgroup contact meta-perceptions & 2.61 & 1.03 & - & & & & & \\
\hline 2. Ingroup contact meta-perceptions & 3.77 & 1.01 & .11 & - & & & & \\
\hline 3. Intergroup contact & 20.19 & 11.21 & $.42 * * *$ & .02 & - & & & \\
\hline 4. Contact quantity & 4.54 & 1.83 & $.36^{* * *}$ & .02 & $.92 * * *$ & - & & \\
\hline 5. Contact quality & 4.24 & 1.01 & $.38 * * *$ & -.05 & $.78 * * *$ & $.51 * * *$ & - & \\
\hline 6. Outgroup attitudes & 68.88 & 17.86 & $.45^{* * *}$ & .05 & $.52 * * *$ & $.41 * * *$ & $.53 * * *$ & - \\
\hline
\end{tabular}

Note. ${ }^{* * *} p<.001$. 
Table 2. Descriptive Statistics and Correlations between Variables, Study $2(N=117)$

\begin{tabular}{|c|c|c|c|c|c|c|c|c|c|c|}
\hline Variable & Mean & $\mathrm{SD}$ & 1 & 2 & 3 & 4 & 5 & 6 & 7 & 8 \\
\hline 1. Outgroup contact meta-perceptions & 3.69 & 0.82 & - & & & & & & & \\
\hline 2. Ingroup contact meta-perceptions & 2.39 & 0.80 & .14 & - & & & & & & \\
\hline 3. Intergroup contact & 14.38 & 11.31 & $.20^{*}$ & .05 & - & & & & & \\
\hline 4. Contact quantity & 3.09 & 2.15 & $.19^{*}$ & .01 & $.97 * * *$ & - & & & & \\
\hline 5. Contact quality & 4.40 & 0.89 & $.21^{*}$ & $.17^{\dagger}$ & $.59^{* * *}$ & $.41^{* * *}$ & - & & & \\
\hline 6. Intergroup anxiety & 2.89 & 1.12 & $-.31 * * *$ & $-.24 * *$ & $-.42 * * *$ & $-.34 * * *$ & $-.59 * * *$ & - & & \\
\hline 7. Outgroup attitudes & 4.13 & 0.78 & $.47^{* * *}$ & $.28^{* *}$ & $.35^{* * *}$ & $.29^{* *}$ & $.44^{* * *}$ & $-.61^{* * *}$ & - & \\
\hline 8. Negative stereotypes & 3.02 & 0.97 & $-.26^{* *}$ & $-.18^{\dagger}$ & $-.27 * *$ & $-.22 *$ & $-.39 * * *$ & $.63^{* * *}$ & $-.63^{* * *}$ & - \\
\hline
\end{tabular}

Note. $\dagger p<.08 ; * p<.05 ; * * p<.01 ; * * * p<.001$. 
Table 3. Indirect effects in the hypothesized model, Study 2

\begin{tabular}{|c|c|c|c|c|c|}
\hline Predictor & First level mediator & $\begin{array}{l}\text { Second level } \\
\text { mediator }\end{array}$ & Dependent variable & $\begin{array}{l}\text { Mean bootstrap } \\
\text { estimate }\end{array}$ & $\begin{array}{l}\text { Percentile confidence } \\
\text { interval }(95 \%)\end{array}$ \\
\hline Outgroup contact meta-perceptions & Intergroup contact & Anxiety & Outgroup attitudes & 0.0347 & {$[0.0040,0.0801]$} \\
\hline Outgroup contact meta-perceptions & Intergroup contact & Anxiety & Negative stereotypes & -0.0524 & {$[-0.1087,-0.0009]$} \\
\hline Outgroup contact meta-perceptions & & Anxiety & Outgroup attitudes & 0.0979 & {$[0.0142,0.1820]$} \\
\hline Outgroup contact meta-perceptions & & Anxiety & Negative stereotypes & -0.1509 & {$[-0.2726,-0.0162]$} \\
\hline Ingroup contact meta-perceptions & - & Anxiety & Outgroup attitudes & 0.0928 & {$[0.0155,0.1871]$} \\
\hline \multirow[t]{3}{*}{ Ingroup contact meta-perceptions } & ----- & Anxiety & Negative stereotypes & -0.1412 & {$[-0.2700,-0.0214]$} \\
\hline & Intergroup contact & Anxiety & Outgroup attitudes & 0.0131 & {$[0.0072,0.0204]$} \\
\hline & Intergroup contact & Anxiety & Negative stereotypes & -0.0199 & {$[-0.0287,-0.0121]$} \\
\hline Outgroup contact meta-perceptions & Intergroup contact & Anxiety & ------ & -0.0974 & {$[-0.2008,-0.0060]$} \\
\hline
\end{tabular}

Note: Mean bootstrap estimates are based on 5,000 bootstrap samples. 
Table 4. Descriptive Statistics and Correlations between Variables, Study 3: Muslim Sample $(N=100)$

\begin{tabular}{|c|c|c|c|c|c|c|c|c|c|c|}
\hline Variable & Mean & SD & 1 & 2 & 3 & 4 & 5 & 6 & 7 & 8 \\
\hline 1. Outgroup contact meta-perceptions & 3.19 & 0.81 & - & & & & & & & \\
\hline 2. Ingroup contact meta-perceptions & 3.62 & 0.87 & $.39 * * *$ & - & & & & & & \\
\hline 3. Intergroup contact & 26.59 & 7.82 & $.42 * * *$ & $.21^{*}$ & - & & & & & \\
\hline 4. Contact quantity & 6.27 & 1.03 & $.26 * *$ & -.02 & $.80 * * *$ & - & & & & \\
\hline 5. Contact quality & 4.18 & 0.86 & $.46^{* * *}$ & $32 * * *$ & $.88 * * *$ & $.44 * * *$ & - & & & - \\
\hline 6. Intergroup anxiety & 1.98 & 0.91 & $-.45 * * *$ & $-.46^{* * *}$ & $-.59 * * *$ & $-.25 *$ & $-.72 * * *$ & - & & \\
\hline 7. Social distance & 2.05 & 0.95 & $-.25 *$ & $-.27 * *$ & $-.36 * * *$ & -.09 & $-.46 * * *$ & $.46^{* * *}$ & - & \\
\hline 8. Negative stereotypes & 1.98 & 0.77 & $-.48 * * *$ & $-.45 * * *$ & $-.51 * * *$ & $-.26 * *$ & $-.56 * * *$ & $.61 * * *$ & $.37 * * *$ & - \\
\hline
\end{tabular}

Note. ${ }^{*} p<.05 ;{ }^{* *} p<.01 ;{ }^{* * *} p<.001$. 
Table 5. Descriptive Statistics and Correlations between Variables, Study 3: Non-Muslim Sample $(N=120)$

\begin{tabular}{|c|c|c|c|c|c|c|c|c|c|c|}
\hline 1. Outgroup contact meta-perceptions & 3.21 & 0.94 & - & & & & & & & \\
\hline 2. Ingroup contact meta-perceptions & 2.93 & 0.75 & $.55^{* * *}$ & - & & & & & & \\
\hline 3. Intergroup contact & 11.27 & 6.73 & $30 * * *$ & $.26^{* *}$ & - & & & & & \\
\hline 4. Contact quantity & 3.41 & 1.51 & $.26^{* *}$ & $.18^{*}$ & $.94 * * *$ & - & & & & \\
\hline 5. Contact quality & 3.08 & 0.82 & $.58 * * *$ & $.33^{* * *}$ & $.78^{* * *}$ & $.59^{* * *}$ & - & & & \\
\hline 6. Intergroup anxiety & 2.54 & 0.94 & $-.56^{* * *}$ & $-.35^{* * *}$ & $-.50^{*}$ & $-.38^{* * *}$ & $-.63^{* * *}$ & - & & \\
\hline
\end{tabular}

Note. ${ }^{*} p<.05 ; * * p<.01 ; * * * p<.001$. 
Table 6. Indirect effects in the hypothesized model, Study 3

\begin{tabular}{|c|c|c|c|c|c|}
\hline Predictor & $\begin{array}{c}\text { First level } \\
\text { mediator }\end{array}$ & $\begin{array}{c}\text { Second level } \\
\text { mediator }\end{array}$ & Dependent variable & $\begin{array}{l}\text { Mean bootstrap } \\
\text { estimate }\end{array}$ & $\begin{array}{l}\text { Percentile confidence } \\
\text { interval }(95 \%)\end{array}$ \\
\hline \multicolumn{6}{|l|}{ Muslims } \\
\hline Outgroup contact meta-perceptions & Intergroup contact & Anxiety & Social distance & -0.0992 & {$[-0.2085,-0.0370]$} \\
\hline Outgroup contact meta-perceptions & Intergroup contact & Anxiety & Negative stereotypes & -0.0585 & {$[-0.1501,-0.0198]$} \\
\hline Ingroup contact meta-perceptions & --- & Anxiety & Social distance & -0.1545 & {$[-0.1525,-0.0380]$} \\
\hline Ingroup contact meta-perceptions & ------ & Anxiety & Negative stereotypes & -0.0910 & {$[-0.2179,-0.0277]$} \\
\hline Outgroup contact meta-perceptions & Intergroup contact & ------ & Negative stereotypes & -0.0709 & {$[-.02011,-0.0036]$} \\
\hline ----- & Intergroup contact & Anxiety & Social distance & -0.0260 & {$[-0.0391,-0.0136]$} \\
\hline ----- & Intergroup contact & Anxiety & Negative stereotypes & -0.0154 & {$[-0.0293,-0.0062]$} \\
\hline Outgroup contact meta-perceptions & Intergroup contact & Anxiety & ------ & -0.2102 & {$[-0.4067,-0.0830]$} \\
\hline \multicolumn{6}{|l|}{ Non-Muslims } \\
\hline Outgroup contact meta-perceptions & Intergroup contact & Anxiety & Social distance & -0.0650 & {$[-0.1320,-0.0260]$} \\
\hline Outgroup contact meta-perceptions & Intergroup contact & Anxiety & Negative stereotypes & -0.0384 & {$[-0.0814,-0.0145]$} \\
\hline
\end{tabular}




\begin{tabular}{|c|c|c|c|c|c|}
\hline Outgroup contact meta-perceptions & ------ & Anxiety & Social distance & -0.2346 & {$[-0.3655,-0.1289]$} \\
\hline Outgroup contact meta-perceptions & ------ & Anxiety & Negative stereotypes & -0.1359 & {$[-0.2141,-0.0788]$} \\
\hline----- & Intergroup contact & Anxiety & Social distance & -0.0255 & {$[-0.0409,-0.0129]$} \\
\hline------ & Intergroup contact & Anxiety & Negative stereotypes & -0.0149 & {$[-0.0251,-0.0073]$} \\
\hline Outgroup contact meta-perceptions & Intergroup contact & Anxiety & ----- & -0.1163 & {$[-0.2144,-0.0514]$} \\
\hline
\end{tabular}

Note: Mean bootstrap estimates are based on 5,000 bootstrap samples. 